\title{
Carnets
}

Revue électronique d'études françaises de l'APEF

Première Série - 4 Numéro Spécial | 2012

Invasions \& Évasions

\section{Quem tem medo dos Franceses?}

\section{Maria de Fátima Marinho}

\section{(2) OpenEdition \\ Journals}

Edição electrónica

URL: http://journals.openedition.org/carnets/7314

DOI: 10.4000/carnets. 7314

ISSN: 1646-7698

\section{Editora}

APEF

Edição impressa

Data de publição: 1 Junho 2012

Paginação: 45-61

Refêrencia eletrónica

Maria de Fátima Marinho, "Quem tem medo dos Franceses? », Carnets [Online], Première Série - 4 Numéro Spécial | 2012, posto online no dia 23 junho 2018, consultado o 20 abril 2019. URL : http:// journals.openedition.org/carnets/7314; DOI : 10.4000/carnets.7314

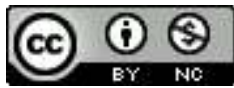

Carnets est mis à disposition selon les termes de la licence Creative Commons - Atribution - Pas d'utilisation commerciale 4.0 International. 


\title{
QUEM TEM MEDO DOS FRANCESES?
}

MARIA DE FÁTIMA MARINHO

Universidade do Porto

msaraiva@letras.up.pt

\begin{abstract}
Resumo
Este ensaio, voluntariamente polémico, equaciona a ambígua relação que, desde cedo, se estabeleceu entre a cultura portuguesa e a sua congénere francesa, a um tempo sedutora e controversa. A uma atitude mais seguidista, característica do século XIX, sucede existência de um espaço cultural comum, talvez o europeu ou o ocidental, que se manifestará em estratégias análogas. $O$ sentimento de pertença mudou de sinal, isto é, instaura-se a sensação de necessidades comuns, de identidades instáveis, de passados recorrentes. E em ambas as literaturas, encontramos processos idênticos, na tentativa de questionar o presente através de um passado em progresso.
\end{abstract}

\begin{abstract}
This essay, meaningfully polemic, equates the ambiguous relationship, both seductive and controversial, which was established, from early days, between Portuguese culture and its French counterpart. To a more dependent attitude, typical of the $19^{\text {th }}$ century, the existence of a common cultural space follows, perhaps European or western, which will translate into analogue structures. The feeling of belonging loses its momentum, i. e., a sense of common needs, instable identities and recurring pasts now rules. And, in both literatures,, we find similar processes of questioning the present through a past in progress.
\end{abstract}

Palavras-chave: influência francesa, romance histórico, identidade, instabilidade.

Keywords: French influence, historical novel, identity, instability. 
Este título, voluntariamente polémico e provocador, com remissão evidente para "Quem tem medo de Virginia Woolf?", deverá ser lido irónica e perversamente. À nostalgia de alguns, saudosos de um tempo de supremacia francesa, acrescenta-se o desprezo de muitos, que não encontram motivações ou seduções para conservar uma postura reverente em relação a uma cultura que deixou de responder às necessidades de um público, mais interessado em assimilar modelos anglo-saxónicos cujo fascínio advém também do uso de uma língua que, por razões comerciais, económicas, militares ou outras, se tornou a língua franca da actualidade, tal como em tempos já o foi o latim, o castelhano ou o francês. Esta mudança de atitude, que acarreta uma alteração no sentimento de pertença a uma comunidade de valores e crenças, terá forçosamente consequências na produção literária ou na relação estética que se estabelece com o outro. Neste pequeno ensaio, tentaremos demonstrar os diferentes avatares que a cultura francesa conheceu em Portugal desde inícios do século XIX até à actualidade, analisando os modos encontrados para lidar com realidades cuja modificação não podemos nem devemos ignorar.

Quando D. Dinis, na célebre cantiga de amor, escreve "Quer eu en maneyra de Proençal" (Dinis s/d: 100) ou quando Eça de Queirós, no texto "O «Francesismo»" (Queirós s/d 20: 813-827), afirma que "Portugal é um país traduzido do francês em vernáculo" ou que "Portugal é um país traduzido do francês em calão" (Queirós s/d 2ª̣: 813), não há dúvidas que, quer o poeta dos séculos XIII-XIV quer o romancista de oitocentos se apercebem da importância da cultura e da influência de além-Pirinéus. A atitude de Eça é mais crítica, mesmo se, e bem o sabemos, ele também se deixa seduzir por esse ambiente e essa literatura, como teremos ocasião de demonstrar. Ele próprio, e no mesmo texto, diz que o acusam de "ser estrangeirado" (Queirós s/d 2: 814) e relata episódios da infância e adolescência onde se vê claramente, mesmo se de forma insidiosa, a obrigatoriedade de se saber francês para aceder a qualquer grau de ensino para além da instrução primária. Vejamos a seguinte passagem e a conclusão do autor de Os Maias:

Começou então a minha carreira social em Lisboa. Mas era realmente como se eu habitasse Marselha. Nos teatros - só comédias francesas; nos homens - só livros franceses; nas lojas - só vestidos franceses; nos hotéis - só comidas francesas...Se nesta capital do Reino, resumo de toda a vida portuguesa, um patriota quisesse aplaudir uma comédia de Garrett, ou comer um arroz de forno, ou comprar uma vara de briche - não podia.

Nem nos palcos, nem nos armazéns, nem nas cozinhas, em parte alguma restava nada de Portugal. Só havia arremedos baratos da França. (Queirós, s/d 2ํ: 818)

Daí, o escritor concluir que "nos tínhamos tornado totalmente franceses" (Queirós s/d 2o: 819). No entanto, e já perto do final do texto, Eça contrapõe a excelência da poesia inglesa em comparação com autores franceses que, no dizer do autor português, fazem 
poesia como quem escreve prosa: "A poesia francesa são alexandrinos em prosa. Baudelaire escrevia primeiro em prosa os seus poemas" (Queirós s/d 2ํ: 825).

Não são precisas mais palavras para percebermos a soberania da França, mesmo descontando a ironia, imbuída de exagero caricatural. Já em 1863, Camilo Castelo Branco, no "Discurso Proemial" de Anos de Prosa, se alongara em considerações sobre os malefícios da leitura, atribuindo a culpa aos romances franceses:

\begin{abstract}
O mau romance tem afistulado as entranhas deste país. (...) Bendita e louvada seja a ignorância! Os romances franceses até 1830, encontraram as almas portuguesas hermeticamente calafetadas. Até esse ano infausto, a mulher era o anjo caseiro, a alma da despensa, a providência da peúga, e sobretudo a fêmea do homem (...). $E$, depois, o malefício do romance não está somente no plagiato irrisório; o pior é quando as imaginações frívolas ou compassivas se entalham os lances da vida fantasiosa da novela, e crêem que a norma geral do viver é essa (Castelo Branco, 1984: 3ํovol., 1031-1033).
\end{abstract}

Estas posturas mordazes e corrosivas denotam inequivocamente a presença francesa na intelectualidade de então. Mais curioso ainda é pensarmos que no início do século XIX, Portugal, à semelhança de muitos outros países europeus, foi invadido pelas tropas napoleónicas e que essas invasões trouxeram a morte e a devastação. Sabemos como a imposição da soberania gaulesa foi acatada no meio nacional ou como se gerou uma ambiguidade inevitável entre o fascínio pelas novas ideias sociais, decorrentes da Revolução francesa, e o repúdio do invasor, responsável pelo aparecimento de textos que iam ao passado buscar a legitimidade de uma nação em perigo de derrocada - falamos do romance histórico romântico e de autores como Alexandre Herculano ou Almeida Garrett.

As atrocidades cometidas pelos soldados marcaram de tal modo a sociedade das primeiras décadas de oitocentos, que abundam escritores, a partir de meados do século XIX e até à actualidade que ilustram o historial desses factos (Marinho 2009), narrando, com maior ou menor detalhe, as três invasões. Só a título exemplificativo, enumeramos os textos que se Ihes referem: sobre a invasão de Junot, destacamos Carlota Ângela, de Camilo Castelo Branco (1858), A Casa dos Fantasmas, de Rebelo da Silva (1865), Os Guerrilheiros da Morte, de Pinheiro Chagas (1872), Paixão de Maria do Céu, de Carlos Malheiro Dias (1902), o 1ํvolume de A Filha do Polaco, de Campos Júnior (1903), El-Rei Junot, de Raul Brandão (1912), Razões de Coração, de Álvaro Guerra (1991), A Casa da Cabeça de Cavalo, de Teolinda Gersão, (1995), “D. Pedro, Defensor do Brasil”, capítulo do livro Fama e Segredo na História de Portugal, de Agustina Bessa-Luís (2006); a invasão de Soult aparece nos romances de Camilo Castelo Branco, Onde Está a Felicidade? (1856), Carlota Ângela (1858), A Enjeitada (1865) e O Demónio do Ouro (1873-4), de Arnaldo Gama, O Sargento-Mor de Vilar (1863) e O Segredo do Abade (1864), de Pinheiro Chagas, Os Guerrilheiros da Morte 
(1872), de Alberto Pimentel, O Anel Misterioso (1873), de Campos Júnior, 2ํㅡ e 3ํvolumes de A Filha do Polaco (1903) e de Mário Cláudio, A Quinta das Virtudes (1990); a invasão de Massena é referida em $O$ Anel Misterioso, de Alberto Pimentel (1873), nos $3^{\circ}$ e $4^{\circ}$ volumes de A Filha do Polaco, de Campos Júnior (1903) e nos contos "O Moleiro de Sula", inserido na recolha de 1954, A Marcha Triunfal, de Júlio Dantas e "Maria Francesa" incluído em Bandeira Preta (1956), de Branquinho da Fonseca.

Alguns exemplos bastarão para percebermos como se passa, de uma visão horrenda e alarmista, para uma visão epistemologicamente mais consentânea com as novas teorias da História. Em A Enjeitada de Camilo Castelo Branco, lemos:

Ó quadra saudosa de patriotismo! Ó guerra dos franceses! Ó heróico Portugal no tempo em que tu eras tão português, tão inimigo de estrangeiros, tão façanhoso contra franceses e tão roupa deles! Ó tempo, tempo em que nem ainda as francesas se podiam tolerar neste abençoado torrão, de onde pululavam Viriatos, como tortulhos bravos quando chove! (...) Nossos pais todos mataram soldados de Napoleão; nossas mães todas mais ou menos tenderam a enxertar-se na genealogia da forneira, que amassava espanhóis como padas de trigo. Isso foi ontem, ontem! - e já hoje todos trajamos à francesa, pensamos francesmente, falamos como pensamos e escrevemos para fazer pensar e rir a posteridade, os nossos bisnetos, uma gente nacionalíssima que não há-de ter nação nenhuma (Castelo Branco, 1986: 185-186).

Já em O Sargento-Mor de Vilar, Arnaldo Gama, com mais preocupações didácticas, limita-se a realçar o espírito patriótico:

Demais, a nação está em pé como um só homem, como um só soldado. O ódio aos franceses é a palavra de alarme em toda a parte. A este grito, Portugueses, de norte a sul, levanta-se armado. Quando as nações chegam a estes pontos de entusiasmo não se conquistam (Gama, 1951a: 75).

No princípio do século XX, um autor como Carlos Malheiro Dias, em Paixão de Maria do Céu, já consegue distanciar-se do relato canónico sobre as tentativas de conquista e de imposição de um governo, sublinhando, por um lado, o alheamento do povo português, por outro, traçando a caricatura de uma sociedade decrépita e necessitadas de transformação:

As mulheres ataram as mãos sobre o penteado francez, desceram-n'as, atarantadas, até ao seio impudicamente desabrochado no decote, á moda luxuriosa do Imperio, e supplicaram aos Céos que contivesse ao longe os matadores de Maria Antonieta e da princesa de Lamballe. Nos recessos da província, velhas fidalgas cahiram em deliquio, cuidando que nunca a guilhotina se desmontara em Paris e entre os ímpios reinavam ainda o tôrvo Marat e o maravilhoso Robespierre (Dias, 1902: 26). 
ou

em Paris, Napoleão mobilisava exércitos, imaginando aterrorisar Portugal. A esse tempo, em toda a terra portugueza, seccava o milho nas eiras e resavam-se as coroas por intenção dos navegantes perdidos no alto mar... (Dias, 1902: 31).

Usando a História como subsidiária em relação à saga familiar que pretende descrever, Mário Cláudio, em A Quinta das Virtudes, constrói um universo onde o emprego obsessivo do condicional proporciona, simultaneamente, um conhecimento prévio do porvir e uma atenuação modelizada desse mesmo conhecimento, imprimindo-lhe um carácter contrafactual.

É esse modo que o narrador vai utilizar para relatar a chegada de Soult, referindo possíveis analogias com a família cuja história se propôs contar e acentuando a pequena valia do exército francês. A narração, entrelaçada já com a interpretação de desejos e necessidades, é devedora de uma posição omnisciente, revelada no uso do condicional e do futuro. Esta postura narrativa, propensa a comentários e a ilações analíticas, facilita a intromissão de um soldado francês que se transformará num focalizador privilegiado da tomada do Porto e respectivo saque. O soldado, personagem preciosa para a narração dos acontecimentos, terá uma atracção, que poderíamos classificar de homossexual, por um soldado português, neutralizando, de certa forma, a animosidade visceral entre os dois povos, que os autores do século XIX querem, a todo o custo, significar:

Começaram grossos pingos de chuva, porém, a salpicar o pó, e abrigando-se à copa de uma carvalheira, lobrigou ele, na penumbra, uma camisa alvíssima, negligentemente desabotoada, até a cintura daquele que a vestia. Era um rapaz da sua idade, de carabina aperrada, com um lampejo, nas pupilas, que ardia, sem que pudesse precisar alguém se de temor, se de ódio. E quedaram-se os dois, assim, na expectativa que dura uma eternidade, e que caracteriza esses encontros, sempre, a que não preside a ideia do próprio desfecho. (...) E, apontando para si mesmo, ousou apresentar-se, enfim, "François", com um sorriso que exprimia a maior ablução. Depôs o outro o fuzil, recuou dois passos, para um certo ponto de claridade, no meio da sombra, onde se the iluminava o louro baço da cabeleira, e articulou, "António", a medo, nominação que the aviam dado, numa tarde de domingo, na pia baptismal. Achegou-se-lhe Bertin, de novo a roçar-lhe o rosto, quase, com o próprio rosto, a aspirar aquele aroma de ervas regadas, que de António se evolava, e que era, muito justamente, o que se desprendia de Rosalie, sua longínqua conversada. Apoiando a dextra, entretanto, no ombro do camponês, pretendeu aflorar-Ihe os lábios, com os próprios lábios, mas recusou-se-lhe o outro, oferecendo-lhe a face (Cláudio, 1990: 125).

É através da focalização de Bertin que sabemos as novidades da campanha, mesmo se o conhecimento é frequentemente parcial ("E dizia-se que, iludido por uma cessação passageira dos disparos, penetrara o general Foy, até às fileiras lusas, (...)", Cláudio 1990: 
126) e decorrente de ideias feitas ou de informações incorrectas. $O$ desastre da ponte das barcas, narrado de forma breve, e porque visualizado pelo soldado francês, não tem a carga dramática a que nos habituámos:

Depois, sob o peso da turbamulta, que se esquivava aos dragões, romperam-se as tábuas e as guardas da ponte das barcas, que ligava o aglomerado portuense a Vila Nova de Gaia, enquanto milhares e milhares iam perecendo, naquele remoinho de lodos e de corpos tragados (Cláudio, 1990: 127).

Deixando agora de lado a ficção com base histórica, passamos de novo ao século XIX e à influência inequívoca da França nas correntes e nos modos de escrever. Poderemos centrarnos em três autores de referência, Almeida Garrett, Camilo Castelo Branco e Eça de Queirós, para estabelecermos a importância dos ecos parisienses. Críticos como Álvaro Manuel Machado (1996) e Vitorino Nemésio (1936), entre outros, já estudaram exaustivamente as relações entre os escritores portugueses e os franceses, demonstrando a evidente filiação daqueles. Limitar-nos-emos a enunciar momentos das obras ou dos seus paratextos, onde os escritores se colocam conscientemente sob a égide da cultura tutelar.

Garrett, numa carta a José Gomes Monteiro, de 12 de Junho de 1833, citada por Teófilo Braga, num texto sobre O Arco de Sant'Ana, diz assim: "Se leu a NOTRE-DAME DE PARIS, de Vítor Hugo é um tanto nesse género o meu romance; se o não leu, aconselho-o que o faça." (Garrett 1966 - I: 212). Na Memória ao Conservatório Real, caracteriza os escritores franceses, dizendo que: "esses escritores (...) alumiam e caracterizam a época, os Vítor Hugos, os Dumas, os Scribes." (Garrett, 2004: 43). Na obra-prima, Viagens na Minha Terra, Garrett não só afirma que escrever romances mais não é do que recortar figurinos de modelos franceses ("vai-se aos figurinos franceses de Dumas, de Eug. Sue, de Vítor Hugo, e recorta a gente, de cada um deles, as figuras que precisa" (Garrett, 2010: 121) ), como alerta para a necessidade de a descrição se adaptar aos cânones:

Que estalagem deve ser esta, hoje no ano de 1843, às barbas de Victor Hugo, com o Doutor Fausto a trotar na cabeça da gente, com os Mistérios de Paris nas mãos de todo o mundo? (Garrett, 2010: 108)

Camilo Castelo Branco, por seu lado, coloca as personagens a ler ou a imitar os franceses: Pedro da Silva, de Os Mistérios de Lisboa, "entusiasmava-se com Lamartine (...) detestava Balzac" (Castelo Branco, 1969: 82-83); D. Catarina, de Coração, Cabeça e Estômago, era "muito lida em Eugénio Sue" (Castelo Branco, 1967: 62); Guilhermina, de Aventuras de Basílio Fernandes Enxertado, "Sabia o Judeu Errante, o Martim o enjeitado, os Mistérios de Paris e andava decorando, em Sintra, a Salamandra. Dizia ela que, a não poder amar um querubim, só amaria Eugénio Sue." (Castelo Branco, 1966: 161); Guilherme do 
Amaral, em Onde Está a Felicidade?, "lera o René, o seu mais predilecto livro dos quinze anos" e um seu amigo jornalista, em conversa com ele, exclama: "Escreve ANÁTEMA nessa parede, como o alquimista de Notre-Dame. Eu serei o Vítor Hugo decifrador desse terrível enigma." (Castelo Branco, 1965: 158 e 244, respectivamente); Custódia, em Eusébio Macário, "andava a ler a tradução dos Mistérios de Paris (Castelo Branco, 2003: 103) e em Memórias do Cárcere, o autor escreve que "O senhor Brito era amado por uma esbelta moça, como Jean Sbogar o fora de uma heroína de Charles Nodier." (Castelo Branco ,1966 1ํ: 243).

Interessante é o caso da "Nota Preambular" de Eusébio Macário, onde Camilo afasta literalmente a influência de Zola, embora se perceba facilmente que tal rejeição é irónica e legitimadora de caricatura:

Pede-se à crítica de escada abaixo o favor de não decidir já que o autor plagiou Emílio Zola. Eusébio Macário não é Rougon Macquart: nem uma família no tempo dos Cabrais é Une famille sous le second empire. Sim, eles, os Cabrais, não são perfeitamente o segundo império (Castelo Branco, 2003: 51).

Casos semelhantes aparecem na obra de Eça de Queirós e percebemos, frequentemente, a ironia aliada a uma evidente matriz literária, mesmo se Eça é disso consciente e disso se afasta, como se pode ver no texto com que iniciámos o presente ensaio. A última frase de O Mandarim, "ó leitor, criatura improvisada por Deus, obra má de má argila, meu semelhante e meu irmão!" (Queirós, 1992b: 191), parafraseia o célebre soneto de Baudelaire e em Correspondência de Fradique Mendes são inúmeras as referências a autores franceses.

O romance $A$ Cidade e as Serras é um exemplo privilegiado de análise caricatural da referida civilização. A descrição da casa da Av. Dos Campos Elísios supera, como é do conhecimento geral, qualquer expectativa mais exigente. Os excessos de maquinaria e de aparente progresso concorrem para legitimar a opção pela província e o regresso feliz a Portugal.

Apesar da tendência dos finais de oitocentos, de reconciliação e elogio dos valores nacionais, a verdade é que houve sempre e paralelamente, às vezes até coincidindo, um deslumbramento pela França. A ligação dos simbolistas às produções de Verlaine, Baudelaire ou Rimbaud são conhecidas, como também não são novidade as estadias de António Nobre e Mário de Sá-Carneiro em Paris, em ambiente intelectualmente estimulante.

Nas vanguardas do início do século XX, não podemos passar em claro a importância do Surrealismo francês e sua exclusiva preponderância sobre o português. Surgido tardiamente, nos finais da década de 40, o movimento português quase não tem originalidade. Já em 1935, Nemésio publicara um livro de poemas em francês, La Voyelle Promise, e Jorge de Sena incluíra, em 1941, no seu livro Perseguição, uma epígrafe de René Char e outra de Breton, o 
que, de certa forma, anunciava a supremacia da influência do autor de L'Amour Fou. As experiências do cadavre exquis e dos diálogos automáticos são decalcadas das constantes nas revistas La Révolution Surréaliste e Le Surréalisme au Service de la Révolution, bem como os manifestos Afixação Proibida e Erro Próprio o são dos Manifestos de Breton (Marinho, 1987). A relação, mesmo em testos poéticos, é, por vezes, tão evidente, que não podemos deixar de a sublinhar. É o caso do texto de Mário Cesariny de Vasconcelos , "os braços sobre a areia", de Pena Capital, que remete para Les Chants de Maldoror, de Lautréamont.

Afirmações semelhantes se poderiam fazer em relação à influência de Sartre e do existencialismo ou do nouveau roman, nos anos sessenta. Antes de começarmos a abordar a nítida mudança de atitude que se começa a fazer sentir nas últimas décadas do século $X X$, gostaríamos apenas de referir dois poemas de Natália Correia, onde se nota já uma transfiguração dos referentes franceses, transfiguração embora, ainda imbuída de sentido de pertença cultural. Ambos de O Anjo do Ocidente à Entrada do Ferro (1973), eles convocam dados inequívocos de referentes inquestionáveis. No poema "Au Petit Niche", podemos ler:

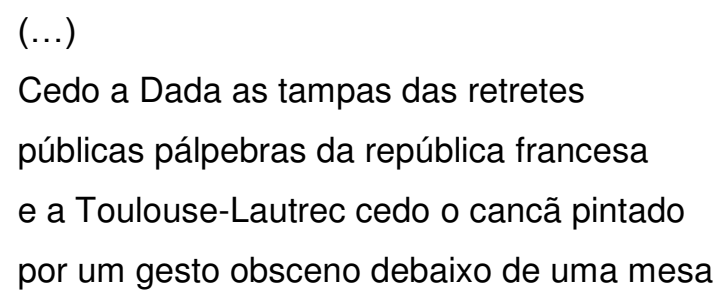

Cedo aos cais uns restos de sonhos embutidos na noite Jean Cocteau ao croissant Versalhes ao bibelô e seja Sartre em molho de manteiga o peixe mais comido no bistrô

O que eu não cedo num nicho deste itinerário varrido por um simum de telexes e ascensores está numa tapeçaria: é a dama do licorne cada vez mais remota pronunciando flores (Correia, 1993: 44-45)

Do outro poema, "Ab lo Temps que fai refreschar lo segle", citarei apenas a primeira estrofe, dada a ligação com o poema de D. Dinis com que iniciamos este estudo:

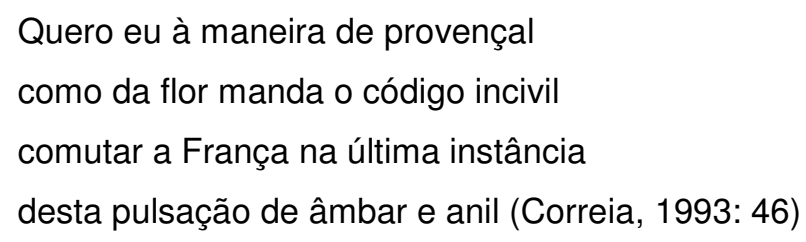


Por esta amostragem da poesia de Natália Correia, percebe-se que já não estamos numa postura seguidista, mas, pelo contrário, se assume a paridade de sentir e de trabalhar o material discursivo. É também neste momento cronológico, o fim dos anos setenta, que se começa a assistir à queda do "império francês", isto é, a uma mudança gradual de paradigma. O repensar da ideia de nação (Sauer e Wright, 2010), em termos muito diferentes do que aconteceu no período romântico, favorece o aparecimento do romance com base histórica, embora nada tenha a ver com o seu antepassado oitocentista, é certo. Apesar de haver processos paralelos e estranhamente semelhantes nas duas literaturas, não podemos falar já de influência ou de preponderância de uma. Devemos sim considerar a existência de um espaço cultural comum, talvez o europeu ou o ocidental, que se manifestará em estratégias análogas. O sentimento de pertença mudou de sinal, isto é, instaura-se a sensação de necessidades comuns, de identidades instáveis, de passados recorrentes. $E$ em ambas as literaturas, encontramos processos idênticos, na tentativa de questionar o presente através de um passado em progresso.

Há várias formas de recorrer a esse passado, sendo a mais simples a que se traduz em processos discursivos que não se afastam muito dos tradicionais, pese embora a mudança de focalização, a relativização do tratamento do material histórico ou o neutro posicionamento em relação a factos ou atitudes. Autores como Fernando Campos, Mário Cláudio, António Cândido Franco (mesmo se dá interpretações simbólicas a todos os pequenos detalhes), Maria Isabel Barreno, João Aguiar, Helena Marques, Luísa Beltrão ou o Mário de Carvalho de Um Deus Passeando pela Brisa da Tarde, poderão preencher esta alínea; em França, podemos falar de Jeanne Bourin, La Chambre des Dames (1979) e Le Jeu de la Tentation (1981), Maurice Denuzière, Louisianne (1977), Louis Gardel, Fort Saganne (1980), Michel Tournier, Le Roi des Aulnes (1970), Michel del Castillo, La Nuit du Décret (1981) ou François-Olivier Rousseau, Sébastien Doré (1985).

De igual forma, a opção por uma primeira pessoa narrativa correspondente a uma personagem histórica, à semelhança do que faz Robert Grave, em 1934, em I Claudius ou Claudius the God, terá o seu correspondente na obra de Marguerite Yourcenar, Mémoires d'Hadrien (1951) e nas dos portugueses Seomara da Veiga Ferreira ou Fernando Campos (Marinho, 1999).

Mais interessantes são os casos em que se transgride o código religioso, instaurando uma perturbação de sinal muito forte.

É essa perturbação que encontramos em romances de Saramago como O Evangelho Segundo Jesus Cristo ou Caim.

Relendo assuntos bíblicos, estas obras subvertem a exegese canónica sem, contudo, modificar a premissa de que partem. A transgressão reside, sobretudo, nos comentários que se fazem e nas interpretações apresentadas para factos e relatos que nos habituámos a ler acriticamente. $O$ sentido de pertença é posto em causa na medida em que a superestrutura 
religiosa assume foros de sagrado e intocável. Ao perder-se a sacralidade ou o espírito que a permite ${ }^{1}$, torna-se possível escrever que "em verdade há coisas que o próprio Deus não entende, embora as tivesse criado" (Saramago, 1991: 27), pondo em causa o mistério que acompanha o sagrado, impedindo o seu questionamento. A cena da expulsão do Éden, a morte de Abel e muitas outras passagens em Caim, bem como os diversos quadros de O Evangelho Segundo Jesus Cristo implicam a destruição do interdito e a sua redução ao factual quotidiano. Transformando em fait-divers episódios destinados a serem lidos sem interpretação ou comentário e criando uma espécie de viagem iniciática para Cristo ou Caim, o narrador destrói a legitimação cristã que esses textos proporcionariam e instaura um clima de desconfiança e de desorientação.

É idêntico o que se passa na obra de Roger Caillois, Ponce Pilates (1961), Gaspard, Melchior \& Balthasar (1980), de Michel Tournier ou La Saga des Rois Mages - La Fève et la Couronne (2006), de Renée-Paule Guillot, assumindo Pôncio Pilatos, Cristo, ou os Reis Magos características de grande humanidade, contrariamente ao que a tradição consagrou.

Finalmente, abordaremos um tipo de romances que revisita obsessivamente o passado, confrontando-o com o presente, na medida em que promove uma voluntária confusão de tempo e lugares em busca de uma identidade perdida. Luis Gonzalo Díez escreve que a reinvenção da identidade obriga a fingir a existência do passado (Díez, 2009: 181) e que este só existe no momento em que pensamos nele, recuperando com a memória a nossa verdadeira identidade, condição essencial de sobrevivência (Da Jandra, 2009: 195).

A consciência de que a ausência de passado se pode revelar trágica (Díez, 2009:15) e de que a história da humanidade se resume grandemente a uma luta constante pela posse do poder (Da Jandra, 2009: 38), a um conflito entre o novo e o velho, entre a tradição e o progresso, pode levar à irrupção de uma paixão pelo proibido, isto é, à sensação de que se torna muito difícil coabitar com um passado que colide com o presente estável mas, frequentemente, falho de atractivos.

O desejo de poder, que o segredo do passado pode estimular e que só termina, obviamente, com a morte (Da Jandra, 2009: 40), acentua-se com o sentido utópico da vivência individual que se obstina em iludir a morte, convocando passados construídos com uma boa dose de imaginação e oportunidade. Paralelamente à construção da identidade individual e colectiva, com a correspondente construção da ideia de nação (Sauer et Wright 2010), encontramos uma sociedade da decepção (Lipovetsky, 2008), que culmina num desencanto ideológico.

Escolhemos para ilustrar esta problemática cinco romances portugueses e três franceses: A Corte do Norte (1987), Eugénia e Silvina (1989), O Concerto dos Flamengos (1994) e Memórias Laurentinas (1996), de Agustina Bessa-Luís; Vícios e Virtudes (2000), de

\footnotetext{
${ }^{1}$ Cf. Da Jandra: 86, «Com el paso del estado de naturaleza al estado de derecho, el individuo no sólo pierde su libertad, sino también su sacralidad».
} 
Helder Macedo; Révolutions (2003), de Le Clézio; Le Cabinet des Merveilles (1995), de Mario Paso; Icare et la Flûte Enchantée (1991), de Julien Burgonde.

Em todas estas obras, encontramos a urgente necessidade de compreender o presente através do passado, tentando frequentemente resolver enigmas que aplacariam a perturbação existencial. A verdadeira identidade de Rosalina de Sousa, confundida com Emília de Sousa, uma actriz, em $A$ Corte do Norte é perseguida em todo o livro e constantemente dissimulada, chegando a haver insinuações sobre a ausência de uma estabilidade de nomeação. Expressões como, "João de Barros, com estas narrativas que nunca tinham fim e pareciam confidências proibidas, interessou-se profundamente pela sua bisavó Rosalina.", dado que "o enigma de Rosalina (...) era completamente óbvio (...) tratava[-se] de uma proposta de linguagem" (Bessa-Luís, 1987: 133 e 241, respectivamente), reflectem a impossibilidade de se estabelecer uma leitura unívoca do passado e de o concluir, isto é, de considerar que os factos de outrora podem ser reversíveis. A frase, "O epílogo desta história não se há-de escrever nunca" (Bessa-Luís, 1987: 271), poderia também aplicar-se a Eugénia e Silvina, romance que evolui em círculos, negando e afirmando a resolução do enigma proposta: foi Silvina parricida? Os argumentos apresentados a favor e contra esta solução, todos de uma lógica irrepreensível, impedem que se chegue a um desenlace satisfatório, implicando uma vertiginosa obsessão (Hamel, 2006) e uma "omnipresença do passado" (Bessa-Luís, 1996: 261), como se pode constatar em Memórias Laurentinas e em Révolutions. A aprendizagem que o conhecimento do passado representa ("Há uma idade em que parece que tudo se conjuga para visitar o passado", Bessa-Luís, 1996: 288) e "o peso da repetição" (Bessa-Luís, 1996: 278) tem um valor acrescido nestes dois romances. Enquanto na obra de Agustina se pode falar de uma "história de vingança que leva um século a consumar" (Bessa-Luís, 1996: 38), em Révolutions, a interligação entre dois tempo, o século XX e a guerra da Argélia e o período depois de 1789 até aos primeiros anos do século XIX, convoca o aparecimento de duas personagens (Jean Eudes e Jean Marro, respectivamente), da mesma família e que vão narrando (um em primeira pessoa, o outro em terceira) as vicissitudes que as ajudam a construir a identidade.

É um abismo perturbador que facilita a emergência do passado e que o institui como fonte imprescindível para a construção do presente: "C'est un sentiment bizarre, être à la fois ici et ailleurs, appartenir à plusieurs histoires" (Le Clézio, 2003: 369). A pertença a várias histórias legitima o aparecimento de dois mundos, de duas épocas em confronto: o século XX da guerra da Argélia e o pós 1789 (fim do século XVIII, início do XIX).

A certeza de que são sentimentos análogos, espaços idênticos, de que tudo mudou mas de que tudo permanece, confere uma funcionalidade própria aos barulhos e aos cheiros que remetem para os universos indistintos de duas épocas. A narração em terceira pessoa, que focaliza o relato através dos olhos de Jean Marro, dá lugar a uma narração em primeira 
pessoa sempre que Jean Eudes, o primeiro membro da família, conta as suas aventuras a seguir à Revolução e a partida para as ilhas Maurícias, lugar utópico para Marro, imaginário de onde emana a consolidação com um passado problemático.

Catherine, a tia-avó, cega, é o elemento catalisador da memória, o elemento que persegue Jean Marro e que o narrador, usando o condicional contrafactual, frequentemente visualiza como o instrumento necessário ao crescimento do protagonista. Logo nas páginas iniciais do romance se afirma que "elle avait choisi Jean pour lui donner sa mémoire" (Le Clézio, 2003: 23) e que todos os seus objectos são "autant de clefs aux mystères du passé" (Le Clézio, 2003: 23). A relação dos dois constitui o núcleo estruturador do romance, até porque ela "semblait être venue tout d'une pièce d'un autre monde, d'un autre temps" (Le Clézio, 2003: 52). É ela quem mora num prédio com o nome de Kataviva, nome mágico, exótico, sem significado, mas pleno de segredos implícitos e sugestivos, segredos que se estendem a Rozilis, o nome do barco que levou a primeira geração às Maurícias e, simultaneamente, o nome da propriedade. É de Rozilis que vêm objectos simbólicos como uma chaleira, um pisa-papéis, uma chávena de Saxe; são de lá as fotografias antigas, aquelas que apelam para a eternização de um momento, de sua natureza fugaz:

Sur les photos ces gens paraissaient invincibles, indéracinables, par la force qui les unissait les uns aux autres; pourtant, si on regardait bien, on percevait un petit frisson, un tremblement léger, parce que c'est l'éternité qui est fragile, pas la vie (Le Clézio, 2003: 51-52).

Apelando constantemente para a memória ("La mémoire est une chose terrible", Le Clézio, 2003: 113), ao ponto de afirmar que há lugares que só existem na memória da tia Catherine, o narrador apresenta-nos o diário da velha senhora, em itálico e estilo telegráfico, mas que desvenda as razões subterrâneas que levaram ao abandono de Rozilis e à quebra de equilíbrio, conducente à ruptura:

Maintenant Jean s'arrête, le cœur battant, la tête pleine de vertige. II est l'endroit exact où la vie de Catherine s'est interrompue, comme si elle y avait laissé une partie d'elle-même, ce jour fatal du $1^{\text {er }}$ janvier 1910, quand avec sa famille elle a été chassée du paradis. (Le Clézio, 2003: 521)

É por oposição a este paraíso perdido que nos aparece o universo de Kataviva, degradado e cruel.

No romance de formação que tem Jean Marro como protagonista, que se sente "à la fois au début et à la fin d'une histoire" (Le Clézio, 2003: 106), há incursões de um passado que condicona o presente. A época conturbada da Revolução francesa, narrada em primeira pessoa pelo primeiro membro activo da família, Jean Eudes, a sua implicação na guerra 
contra a Inglaterra, a partida com a mulher e a filha recém-nascida para as Maurícias e posterior instalação na ilha, têm como contraponto a guerra da Argélia e a partida de Jean Marro para Londres e o México. Aliás, as duas guerras são narradas, frequentemente, de modo idêntico, usando-se os diários, em itálico, sucintos, telegráficos, sem quase redacção mas apenas enumeração factual. Aliás, o artifício da verosimilhança, traduzido pelo uso do calendário revolucionário ("Du 20 au 30 ventôse l'na VI", Le Clézio, 2003: 183) ou pela adopção de grafia antiga ("midy", "tems", Le Clézio, 2003: 186), aliado ao uso do itálico que pode significar uma pretensa transcrição fiel sem intromissões do narrador ou do ficcional, contribuem para criar a ambiguidade pretendida: são dois tempos mas é um único tempo, que se repete, que repete as condições de vida, os sentimentos, as opiniões, as injustiças, os meandros da condição humana.

Esta correspondência ou interferência entre dois tempos, que é também visível em Icare ou la Flûte Enchantée, onde o narrador, de repente, está no tempo de Mozart, sem contudo deixar de ter os conhecimentos do presente, atinge um elevado grau de construção nos três romances de que ainda não falámos. O facto de Luísa, de O Concerto dos Flamengos, só conseguir sublimar as suas frustrações identificando-se com Isabel de Portugal, filha de D. João I, casada com Filipe o Bom da Borgonha ou de a sociedade novecentista corresponder à da corte da mãe de D. Sebastião (Vícios e Virtudes), implica uma subversão das coordenadas da linearidade. Quando se lê que "Luísa Baena viu no espelho fosco da cómoda (...) um rosto que desconhecia" (Bessa-Luís, 1994: 48) ou quando se nota uma perturbadora coincidência de nomes e se afirma que "A História repete-se" (Macedo, 2000: 26), considerando que "é necessário ir criando espaço para o passado que mais convém ao nosso futuro" (Macedo, 2000:12), não podemos ignorar a importância da transgressão e suas consequências ao nível narrativo e da correspondente construção da identidade. É que, a acreditarmos em Helder Macedo, "O passado (...) era o tempo da imposta identidade" (Ibid.: 69), o que significa que "não podia lembrar-se do que se lembrava" (Ibid.: 37), dado que é preciso "aceitar que cada história pode conter a história oposta" (Ibid:: 43-44). Esta noção, fundamental para compreendermos as hesitações e perturbações de um presente angustiante, justificam a problemática exposta no último romance, La Cabinet des Merveilles. A obra fala sobretudo de um móvel, um contador com sete gavetas, que representariam sete diferentes cidades europeias (aliás, os títulos dos capítulos, "Premier Tiroir, Deuxième Tiroir, etc" são disso prova). Pertencendo sempre a pessoas diferentes, desde o fim do século XVIII até à actualidade, o móvel encerra em cada uma das gavetas diferentes segredos, que vão sendo erroneamente interpretados pelos sucessivos proprietários. As falsas leituras do passado (à semelhança do romance espanhol, El Sueño de Venecia, de Paloma Diáz-Mas) demonstram o logro em que se pode incorrer e retiram credibilidade à reconstrução. As dúvidas sobre a veracidade de objectos 
tidos como sagrados ou a canonização de personagens de existência duvidosa, destroem crenças e fazem perigar certezas:

On a canonisé des gens qui n'avaient point existé; on peut bien embaumer des gens qui n'étaient pas saints du tout, parce qu'ils eurent assez de malice pour dissimuler leurs fautes ou que l'on se méprit sur leur valeur (Paso, 1995: 69).

Não nos interessa aqui discutir o modo como o passado se presentifica em textos contemporâneos ou quais os processos discursivos empregues para levar a cabo uma releitura de temas e mitemas esgotados. Interessa-nos sim apreender a semelhança de modi faciendi entre autores franceses e portugueses, acentuando a ausência de influências explícitas. Num tempo de «desaparecimento» do francês, que o título do romance de Assia Djebar, La Disparition de la Langue Française assume simbolicamente, convém descortinar a importância do conhecimento recíproco, sublinhando a inoperância decorrente da ignorância e da pretensa atitude utilitária. 


\section{Bibliografia}

BesSA-Luís, Agustina (1987). A Corte do Norte. Lisboa: Guimarães Editores. (1989). Eugénia e Silvina. Lisboa: Guimarães Editores. (1994). O Concerto dos Flamengos. Lisboa: Guimarães Editores. (1996). Memórias Laurentinas. Lisboa: Guimarães Editores.

(2006). Fama e Segredo na História de Portugal. Lisboa: Guerra e Paz

\section{Editores.}

BouRIN, Jeanne (1979). La Chambre des Dames. Paris : Editions La Table Ronde, " Le Livre de Poche".

(1981). Le Jeu de la Tentation. Paris : Editions La Table Ronde, " Le Livre de

Poche ".

BRANDÃO, Raul (2007). El-Rei Junot, edição de Maria de Fátima Marinho. Lisboa: Relógio d'Água [1912].

BuRGONDE, Julien (1991). Icare et la Flûte Enchantée. Arles : Babel.

CAILloIS, Roger (1994). Poncio Pilatos - El Dilemma del Poder. Trad. castelhana de Miguel de Hernani. Barcelona: Edhasa [1961].

CAMPos JúNIOR (1926). A Filha do Polaco. Lisboa: João Romano Torres \& C ${ }^{\mathrm{a}}$ Editores [1903], 4 Vols.

Castelo Branco, Camilo (1918). Carlota Ângela. Lisboa: Parceria António Maria Pereira [1858].

(1965). Onde Está a Felicidade?. Lisboa: Parceria António Maria Pereira,

[1856].

$\left(1966^{a}\right)$. Aventuras de Basílio Fernandes Enxertado. Lisboa: Parceria António

Maria Pereira [1863].

(1966 $)$. Memórias do Cárcere. Lisboa: Parceria António Maria

Pereira, 2 vols. [1862].

(1967). Coração, Cabeça e Estômago. Lisboa: Parceria António Maria Pereira [1862].

(1969). Os Mistérios de Lisboa. Lisboa: Parceria António Maria Pereira, 3 vols.

[1854].

(1970). O Demónio do Ouro. Lisboa: Parceria António Maria Pereira, [1873-74],

2 vols.

(1984). Anos de Prosa, Obras Completas. Porto: Lello \& Irmão - Editores

[1863].

(1986). A Enjeitada, Obras Completas. Porto: Lello \& Irmão, Vol. V [1865]. 
(2003). Eusébio Macário / A Corja, prefácio e fixação de texto de J. Cândido

Martins. Porto: Caixotim [1879 / 1880].

CASTILlO, Michel del (1981). La Nuit du Décret. Paris: Seuil, Coll. Points.

Cesariny de Vasconcelos, Mário (1982). Pena Capital. Lisboa: Assírio e Alvim [1957].

CHAGAS, Manuel Pinheiro (1872). Os Guerrilheiros da Morte. Lisboa: Escriptorio da

Empresa.

CLÁUDIO, Mário (1990), A Quinta das Virtudes. Lisboa: Quetzal.

CoRREIA, Natália (1993), O Sol nas Noites e o Luar nos Dias II. Lisboa: Projornal.

DA JANDRA, Leonardo (2009). La Gramatica del Tiempo. Oaxaca (México): Ed. Almadía.

DANTAS, Júlio (s/d). "O Moleiro de Sula", in Marcha Triunfal - Narrativas da epopeia militar portuguesa do século XII ao século XX, Lisboa: Livr. Bertrand, [1954].

DENUZIÈRE, Maurice (1977). Louisiane. Poitiers : Editions Jean-Claude Lattès.

DIAS, Carlos Malheiro (1902). Paixão de Maria do Céo. Lisboa: Livraria Editora Tavares Cardoso \& Irmão.

DíAZ-MAS, Paloma (1992). El Sueño de Venecia. Barcelona: Anagrama.

DíEZ, Luis Gonzalo (2009). Los Convencionalismos del Sentimiento. Barcelona: Circulo de Lectores S.A.

DINIS, El Rei D. (s/d), Cancioneiro da Biblioteca Nacional (Colocci-Brancuti), leitura, comentários e glossário de Elza Paxeco Machado e José Pedro Machado. Lisboa: Edição de Álvaro Pinto (Revista de Portugal), Volume III.

DJebar, Assia (2003). La Disparition de la Langue Française. Paris : Albin Michel.

FONSECA, Branquinho da (s/d). "Maria Francesa", in Bandeira Preta. Lisboa: Portugália Ed. [1956].

GAMA, Arnaldo (1951a). O Sargento-Mor de Vilar. Porto: Livraria Simões Lopes de Manuel Barreira Editor [1863].

(1951b). O Segredo do Abade. Porto: Livraria Simões Lopes de Manuel Barreira

Editor [1864].

GARDEL, Louis (1980). Fort Saganne. Paris: Seuil.

GARRETt, Almeida (2004). Frei Luís de Sousa, prefácio de Annabela Rita. Porto: Caixotim [1844].

(1966). Obras, 2 vols. Porto: Lello \& Irmão Editores.

(2004). O Arco de Sant'Ana, edição de Maria Helena Santana. Lisboa: Imprensa

Nacional - Casa da Moeda [1845-1850].

(2010). Viagens na Minha Terra, edição de Ofélia Paiva Monteiro. Lisboa,

Imprensa Nacional - Casa da Moeda [1846].

Grave, Robert (1953). I Claudius. Londres: Penguin Books [1934].

(1954). Claudius the God. Londres: Penguin Books [1934].

GuerRA, Álvaro (1991). Razões de Coração. Lisboa: Publicações Dom Quixote. 
Guillot, Renée-Paule (2006). La Saga des Rois Mages - La Fève et la Couronne. Monaco : Editions Alphée.

HAMEL, Jean-François (2006). Revenances de l'Histoire - Répétition, Narrativité, Modernité.

Paris : Editions de Minuit.

LAUTREAMONT, Comte de (1969). CEuvres Complètes. Paris : Garnier / Flammarion.

LE CLeZIO, J.M.G. (2003). Révolutions. Paris : Gallimard.

LIPOVETSKY, Gilles (2008). La Sociedad de la Decepción - Entrevista com Bertrand Richard, traduction de Antonio-Prometeo Moya. Barcelona: Editorial Anagrama [2006].

MACEDO, Helder (2000). Vícios e Virtudes. Lisboa: Editorial Presença.

MACHAdO, Álvaro Manuel (1996). Do Romantismo aos Romantismos em Portugal - Ensaios de tipologia comparativista. Lisboa: Editorial Presença.

MARINHO, Maria de Fátima (1987). O Surrealismo em Portugal. Lisboa: Imprensa Nacional Casa da Moeda.

(1999). O Romance Histórico em Portugal. Porto: Campo das Letras. (2009). "A Memória e a Ficção da Segunda Invasão Francesa", O Porto e as Invasões Francesas 1809-2009, coordenação editorial Professor Valente de Oliveira. Porto:

Público - Comunicação S.A. / Câmara Municipal do Porto, Vol. IV, pp.205-231.

NEMÉSIO, Vitorino (1936). Relações Francesas do Romantismo Português. Coimbra:

Biblioteca da Universidade.

PAso, Mario (1995), Le Cabinet des Merveilles. Paris : Editions Denoël.

PIMENTEL, Alberto (1873). O Annel Mysterioso. Lisboa: Escriptorio da Empresa.

QUEIRÓs, Eça de $\left(1992^{\mathrm{a}}\right)$. A Capital! (Começos duma carreira), edição de Luís Fagundes

Duarte. Lisboa: Imprensa Nacional - Casa da Moeda [1925, póstumo]. (s/d). Obras, 3 vols. Porto: Lello \& Irmão.

(1992b). O Mandarim, edição de Beatriz Berrini. Lisboa: Imprensa Nacional -

Casa da Moeda [1869]

RoussEAU, François-Olivier (1985). Sébastien Doré. Paris: Gallimard, Coll. " Folio ”.

SARAMAGo, José (1991). O Evangelho Segundo Jesus Cristo. Lisboa: Caminho. (2009). Caim. Lisboa: Caminho.

SAUER, Elizabeth e WRIGHT, Julia M. (eds.). (2010). Reading the Nation in English Literature: A Critical Reader. Londres e Nova lorque: Routledge.

SILVA, Luís Augusto Rebelo da (1908). A Casa dos Phantasmas. Lisboa: Livraria Barateira, [1865], 2 Vols..

TOURnier, Michel (1970). Le Roi des Aulnes. Paris : Gallimard, Coll. “ Folio “. (1980). Gaspard, Melvhior \& Balthasar. Paris: Gallimard, Coll. "Folio". YouRCENAR, Marguerite (1974). Memórias de Adriano, trad. portuguesa de Maria Lamas. Lisboa: Ed. Ulisseia [1951]. 
